\title{
La génesis de los paseos litorales: el caso de la fachada marítima urbana de Alicante
}

Olga Grao-Gil 1

Recibido: 10-05-2019 | en su versión final: 04-01-2020

Resumen

La definición, secuencial y estructurada, de las diferentes circunstancias que han dado lugar a los paseos que conforman hoy la fachada marítima de la ciudad de Alicante es el objetivo principal de este artículo. Si bien los paseos litorales son hoy los puntos de referencia de nuestras ciudades costeras, eminentemente turísticas, la bibliografía al respecto es escasa. Los resultados de este estudio contribuirán al entendimiento del fenómeno de su génesis, como fragmentos urbanos en relación con la historia y desarrollo del resto de la urbe, así como aportarán un mayor conocimiento de la problemática de su vertebración y del importante papel que juegan en el futuro inmediato de la ciudad. Para entender el proceso de conformación de los paseos litorales es necesario estudiar la evolución del frente marítimo y su entorno, así como los acontecimientos históricos, sociales, culturales y políticos que han influido en su devenir. Se trata de una investigación en la que, mediante el estudio pormenorizado de cada uno de los elementos que conforman la fachada costera, se analizan los cambios morfológicos experimentados por ésta, de acuerdo con la variable función que ha desempeñado a lo largo del tiempo. El rol predominante de la fachada marítima alicantina durante siglos fue el defensivo, sirviendo simultáneamente de marco al puerto. En el siglo XIX, con la llegada del ferrocarril, el auge de los baños de mar y el derribo de las murallas, la función de defensa fue sustituida por la lúdico-representativa que, aunque con modificaciones, permanecerá hasta nuestros días.

Palabras clave: Frente costero; paseo litoral; waterfront, explanada

Citación

Grao-Gil, O. (2020). La génesis de los paseos litorales: el caso de la fachada marítima urbana de Alicante, ACE: Architecture, City and Environment, 14(42), 8271. DOl: $\underline{\text { http://dx.doi.org/10.5821/ace.14.42.8271 }}$

1 Dra. Arquitecta, Profesora asociada del Departamento de Edificación y Urbanismo de la Universidad de Alicante. (ORCID: 0000-0003-1994-9331). Correo de contacto: olga.grao@ua.es

ACE, 14 (42) CC BY-ND 3.0 ES | UPC Barcelona, España | La génesis de los paseos litorales: el caso de la fachada marítima urbana de Alicante. DOI: http://dx.doi.org/10.5821/ace.14.42.8271 


\title{
The genesis of the seafronts: the case of the urban maritime façade of Alicante
}

Abstract

\begin{abstract}
The definition, sequential and structured, of the different circumstances that have given rise to the promenades that today shape the urban maritime façade of Alicante is the main objective of this article. Although seafronts are today the reference landmarks of our coastal cities, eminently tourist, the literature in this regard is scarce. The results of this study will contribute to the understanding of the phenomenon of its genesis, as urban fragments in relation to the history and development of the rest of the city, as well as contribute a greater knowledge of the problems of its structuring and the important role they play in the immediate future of the city. In order to understand the process of shaping littoral promenades, it is necessary to study the evolution of the seafront and its environment, as well as the historical, social, cultural and political events that have influenced its transformation. This is an investigation in which, through the detailed study of each of the elements that make up the coastal façade, the morphological changes experienced by it are analysed, according to the variable function that it has played over time. The predominant role of the Alicante maritime façade for centuries was defensive, simultaneously serving as a frame to the port. In the nineteenth century, with the arrival of the railway, the rise of the sea baths and the demolition of the walls, the defence function was replaced by the playful-representative one that, although with modifications, remains to this day.
\end{abstract}

Keywords: Seafront; littoral façade; waterfront; promenade

\section{Introducción}

Las fachadas marítimas o waterfronts, es decir, "el modo en que la ciudad se presenta en su límite con el mar" (Blasco et al., 1996, pág. 365), aparecen convertidas hoy en escaparate de las ciudades litorales. Tras largos siglos de predominio de la función defensiva y portuaria, el desarrollo morfológico urbano en el interfaz tierra-mar dio lugar, como en el caso de Alicante, a la aparición de nuevos espacios de recreo paralelos a la costa, junto al puerto y el mar, en la segunda mitad del siglo XIX. Tal fue la primacía de estos nuevos paseos, frente a los tradicionales del casco histórico consolidado (Martínez, 1998), que llegaron a acaparar el protagonismo social, económico y cultural de la ciudad. Buena parte de la burguesía alicantina de finales del siglo XIX y principios del XX eligió establecer su residencia en torno a ellos y no solo en las nuevas avenidas interiores del Ensanche, como ocurriría en otras ciudades. Se podría decir que se trató de una intervención urbanística de éxito: todo aquel que tenía ocasión frecuentaba estos lugares y durante décadas el frente litoral se erigió como el lugar más representativo de la ciudad. Aunque con altibajos a lo largo del tiempo, los paseos marítimos urbanos se postulan como uno de los ejes principales de proyección de la ciudad moderna.

Para comprender el proceso que originó esos espacios públicos costeros es importante analizar su evolución en su contexto histórico, sin olvidar la interrelación con el resto de la urbe. Se plantea como hipótesis de partida que la génesis de estos paseos marítimos es consecuencia de los cambios funcionales del frente litoral, de la que se desprenden las preguntas de investigación siguientes: ¿la 
aparición de los paseos litorales urbanos se derivó de un cambio de función en la fachada marítima? y ¿en qué momento y por qué se produjo ese cambio de función? Alicante, primera ciudad costera española comunicada por ferrocarril con la capital, es el caso de estudio de nuestra investigación.

En relación al ámbito temporal, si bien se hace un recorrido somero partiendo del origen de la ciudad, se centrará en el periodo que abarca desde el derribo de las murallas en el siglo XIX hasta nuestros días. Con respecto al ámbito espacial, el estudio se limita a la fachada marítima urbana que enmarca el casco histórico y los barrios céntricos adyacentes, tomando como extremos las antiguas estaciones - recuerdo de la importancia del ferrocarril- de La Marina, al noreste, y de Murcia, al sureste. Se considera la fachada marítima urbana dividida en tres tramos diferenciados, coincidentes con tres paseos: Gómiz-Explanada-Canalejas, de $2 \mathrm{~km}$ aproximadamente de longitud total.

El presente artículo deriva de un estudio de mayor envergadura que analiza la génesis de la fachada marítima urbana de Alicante, abarcando un análisis cronológico más amplio, así como el estudio detallado de la arquitectura y desarrollos urbanos implicados más relevantes, lo que ha permitido una comprensión profunda de la problemática planteada.

Las fuentes consultadas, como la bibliografía sobre la arquitectura y los orígenes de la ciudad de Alicante, los escritos de los cronistas de la villa, así como las colecciones fotográficas del Archivo Municipal de Alicante, mencionan el frente litoral de soslayo. Esta investigación trata de reordenar esa información, estructurarla y darle continuidad para, comprendiendo el presente de la fachada costera, poder proyectar su futuro.

\section{Evolución del frente litoral en su contexto histórico: la función defensiva}

El actual enclave de la ciudad de Alicante tiene su origen en la primitiva villa musulmana surgida tras el Pacto de Tudmir ${ }^{1}$ del año 713. Se trataba de un asentamiento encintado de reducido tamaño, Laquant, situado entre el mar Mediterráneo y el monte Benacantil, coronado por una alcazaba en lo alto, que a día de hoy permanece como elemento simbólico de referencia (Ramos, 1984).

Alicante fue siempre ciudad amurallada. El primer anillo mural musulmán, que englobaba la medina - Vila Vella, se vería desbordado en época medieval por el aumento de población, que dio lugar a la ampliación de la ciudad, conformando la Vila Nova (Figura 1). Un nuevo perímetro de murallas se fue levantando a partir del siglo XIII, englobando al existente que se había revelado insuficiente, culminándose en el siglo XVI, época de bonanza económica, con nuevas puertas, baluartes y torreones defensivos (Rosser, 1990).

Desde sus orígenes, debido en gran medida a los límites que la orografía y el propio mar imponían, la ciudad se fue extendiendo hacia el llano siguiendo la línea de la costa, junto a un puerto que cada vez fue cobrando mayor protagonismo. Con respecto a la fachada marítima, se componía de unas murallas costeras que defendían la villa de los ataques por mar, que se prolongaron conforme fue necesario (Figura 1). Destacar que en este lienzo costero se abría desde antiguo una puerta que conectaba la villa con el puerto, la Puerta del Muelle o del Mar (Bendicho, 1653).

Será durante el siglo XVI cuando, temiendo por la seguridad de los puertos mediterráneos del sur, vulnerables al ataque de piratas como Barbarroja (González, 2012), se decidió fortalecerlos militarmente dando prioridad a las murallas junto al mar. Se levantaron nuevos lienzos que

\footnotetext{
1 El Pacto de Tudmir o de Teodomiro firmado entre Abd al-Aziz ibn Musa, hijo del gobernador del norte de África, y Teodomiro, noble visigodo, el 5 de abril del año 713 dio lugar a un territorio de dominio musulmán con cierta autonomía, que serían aproximadamente las actuales provincias de Alicante y Murcia.
} 
englobaron a los anteriores, discurriendo aproximadamente de forma paralela a los existentes, pero más próximos a la costa (Figura 1). Se respetaron las murallas medievales por motivos estratégicos, de manera que si fallaban los nuevos muros siempre habría una segunda línea de defensa en el interior. No obstante, los rápidos avances en artillería e ingeniería militar, sumado al imparable crecimiento de los arrabales extramuros, provocaron que la nueva estructura defensiva quedara pronto obsoleta. Así se pondría de manifiesto cuando el fatídico bombardeo sobre Alicante de la armada francesa en el verano de 1691 arrasara literalmente la ciudad.

Figura 1. Esquema de las desaparecidas murallas de la costa sobre cartografía actual

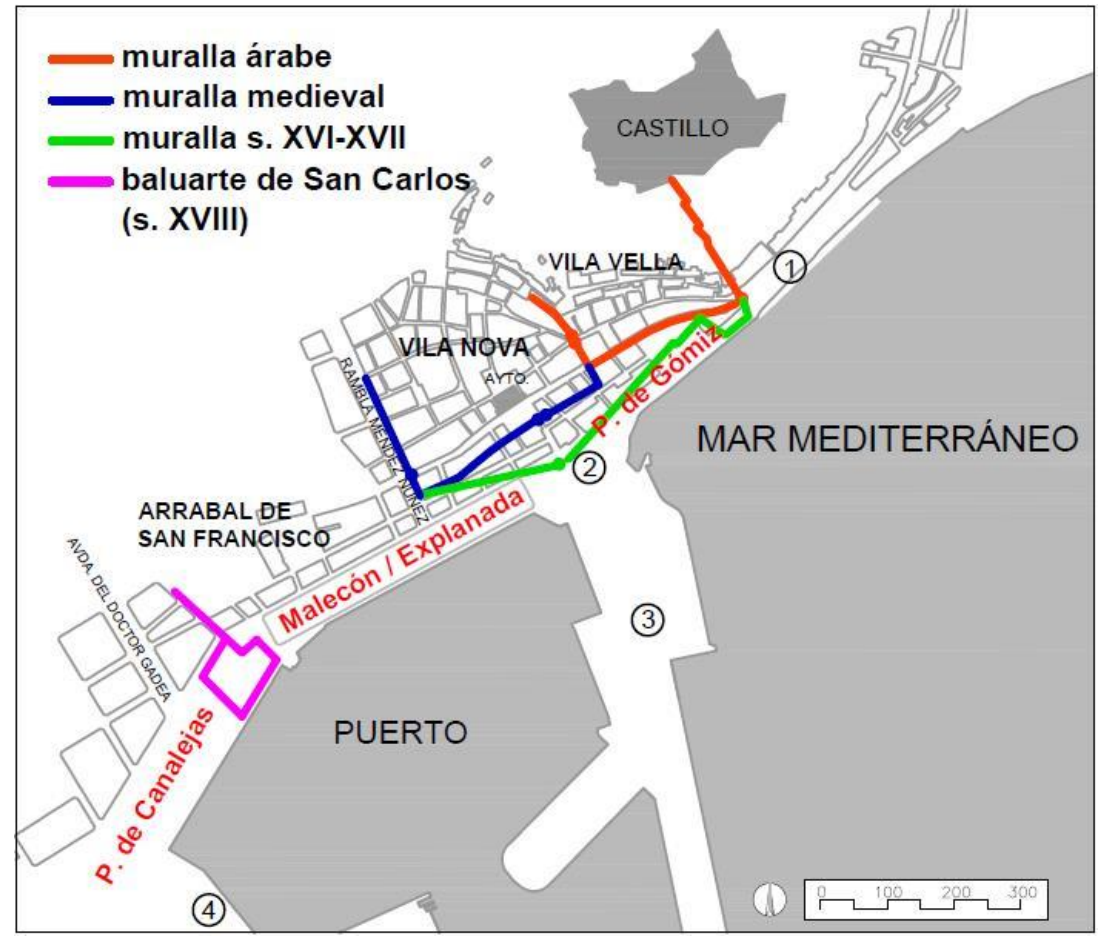

Nota: 1. Playa del Postiguet; 2. Puerta del Mar o del Muelle; 3. Muelle de Levante; 4. Muelle de Poniente Fuente: elaboración propia a partir del estudio de la cartografía histórica de Alicante. 2019.

Alicante se adentrará en el siglo XVIII todavía recuperándose de la debacle que supuso el ataque francés. Unos meses después del bombardeo, siendo conscientes de la necesidad de defender la ciudad por occidente y de la falta de protección del cada vez más extenso arrabal junto a la costa, el de San Francisco, las autoridades decidieron edificar el baluarte de San Carlos, que sería la última gran obra defensiva antes del derribo total de las murallas (Figura 1). Gran cantidad de los escombros resultado del bombardeo fueron depositados en la línea de costa, ganando algo de terreno al mar y originando una nueva zona de la ciudad, el Malecón —actual paseo de la Explanada-.

A principios del siglo XIX, tras la Guerra de Independencia que había dejado patente la estructura defensiva desfasada de la ciudad, se levantó un último anillo de protección. En el frente marítimo se unió el baluarte de San Carlos por la línea de la costa con el resto de puertas de la muralla litoral. Poco habría de durar ya que, sin que las autoridades militares pudieran impedirlo, los torreones fueron destinados a otros usos y las murallas se convirtieron en lugar de vertido de escombros. La función defensiva estaba llegando a su fin y con ello el inicio de las grandes transformaciones del siglo XIX que, como veremos, dieron inicio al desarrollo de otro tipo de función en el espacio litoral.

ACE, 14 (42) CC BY-ND 3.0 ES | UPC Barcelona, España | La génesis de los paseos litorales: el caso de la fachada marítima urbana de Alicante. DOI: http://dx.doi.org/10.5821/ace.14.42.8271 


\section{El binomio puerto-ciudad: la función comercial}

Desde su fundación, la historia de la ciudad de Alicante ha estado íntimamente ligada a su puerto y a la actividad comercial que en él se ha desarrollado. A diferencia de otras ciudades litorales de la región sin expresa vocación urbana marítima, como Castellón o Valencia (Martí et al., 2018), el asentamiento marinero o grao ${ }^{2}$ lo constituye el propio centro urbano, puesto que la ciudad se desarrolló junto a su puerto y su mar (Reyero, 2014).

Considerado uno de los más seguros, en cuanto a la estabilidad de sus diques, del Mediterráneo occidental, el primer escrito documentado que habla del puerto en su emplazamiento actual data de 1433. Si bien, ya en 1271 el rey Alfonso X el Sabio declaró Alicante como Puerto Público del Mediterráneo. El muelle original del siglo XIII, con una longitud de 200 pasos, ya estaba situado donde hoy se encuentra el actual muelle de Levante, aunque probablemente se trataría de una sencilla estructura de madera que se adentraba en la bahía para facilitar el atraque de las embarcaciones y la carga y descarga de mercancías (Subirá, 1987). A partir de entonces, y casi hasta finales del siglo XIX, la fachada marítima de Alicante se compondrá de unas murallas costeras que protegían la urbe en su encuentro con el mar, en las que destacaba la puerta de entrada desde el puerto (Puerta del Mar) junto a un modesto muelle, que con los años irá ganando en tamaño, longitud y capacidad.

A partir del siglo XIV se inició un periodo de intensa actividad mercantil y ya a finales del XV el puerto de Alicante era el segundo del país, después del de Valencia, con representaciones comerciales de muchos puertos europeos en la ciudad. No es casual que en el año 1490 el rey Fernando el Católico concediera a Alicante el título de ciudad, en gran medida motivado por su puerto, como indicaba el cronista Martin de Viciana (1564): “[...] por haber servido valerosamente en la guerra de Granada y que Alicante estaba en el paraje muy importante del reyno para tiempo de guerra y para cargar y descargar mercaderías por tener tal y tan buena y segura playa y muelles [...]". Tras el descubrimiento de América, los puertos del Atlántico cobraron mayor importancia, si bien Alicante mantuvo su relevancia por servir de punto de escala. A mediados del siglo XVII la longitud aproximada del muelle era de 80 - 100 metros, aunque la escasa profundidad obligaba a los barcos a permanecer fondeados en la rada. Seguirá siendo en este siglo uno de los principales puertos de España, exportador de productos agrarios locales y castellanos y redistribuidor de mercancías procedentes de América.

Es posible hacerse una idea de la estructura que componía el Alicante del setecientos gracias a un grabado de 1693 - que se conserva en la catedral de Valencia - en el que están representadas las defensas de la ciudad, su castillo en lo alto del cerro y las murallas, así como un dique embarcadero que parte de una de las puertas de la villa, la Puerta del Mar o del Muelle, flanqueada por dos torreones (Figura 2). Aparece un anillo defensivo al estilo renacentista, jalonado por bastiones, del que solo se materializaría uno, el más meridional, conocido como baluarte de San Carlos. El muelle a poniente, aunque aparece representado, no se levantaría hasta varios siglos después.

Durante el siglo XVIII, la actividad portuaria de Alicante fue en aumento a la vez que la ciudad experimentaba un gran desarrollo y un notable incremento de población. El puerto seguía constituido por un pequeño muelle junto a la ciudad, que resultaba completamente insuficiente para abarcar el volumen de tráfico que debía soportar. Urgía realizar obras de mejora para ensancharlo y prolongarlo, alguna de las cuales se llevaron a cabo parcialmente. En la segunda mitad de este siglo, como ocurriría en gran parte de la geografía española, impulsados por el academicismo naval y militar, se realizaron numerosos proyectos y planes teóricos para reformar el puerto que, si bien nunca se

\footnotetext{
${ }^{2}$ Grao, según la RAE, playa que sirve de desembarcadero. Voz muy común en el litoral mediterráneo para hacer referencia a los puntos costeros que sirven de embarcadero y que a menudo han originado barrios marítimos de un pueblo o ciudad, como desdoblamiento portuario, situado normalmente a no más de $10 \mathrm{~km}$ de distancia.
} 
llegaron a ejecutar por la crisis político-económica, dan buena muestra de la importancia que las autoridades daban a la actividad portuaria (Campos, 2007).

Figura 2. Grabado de la ciudad de Alicante. 1693

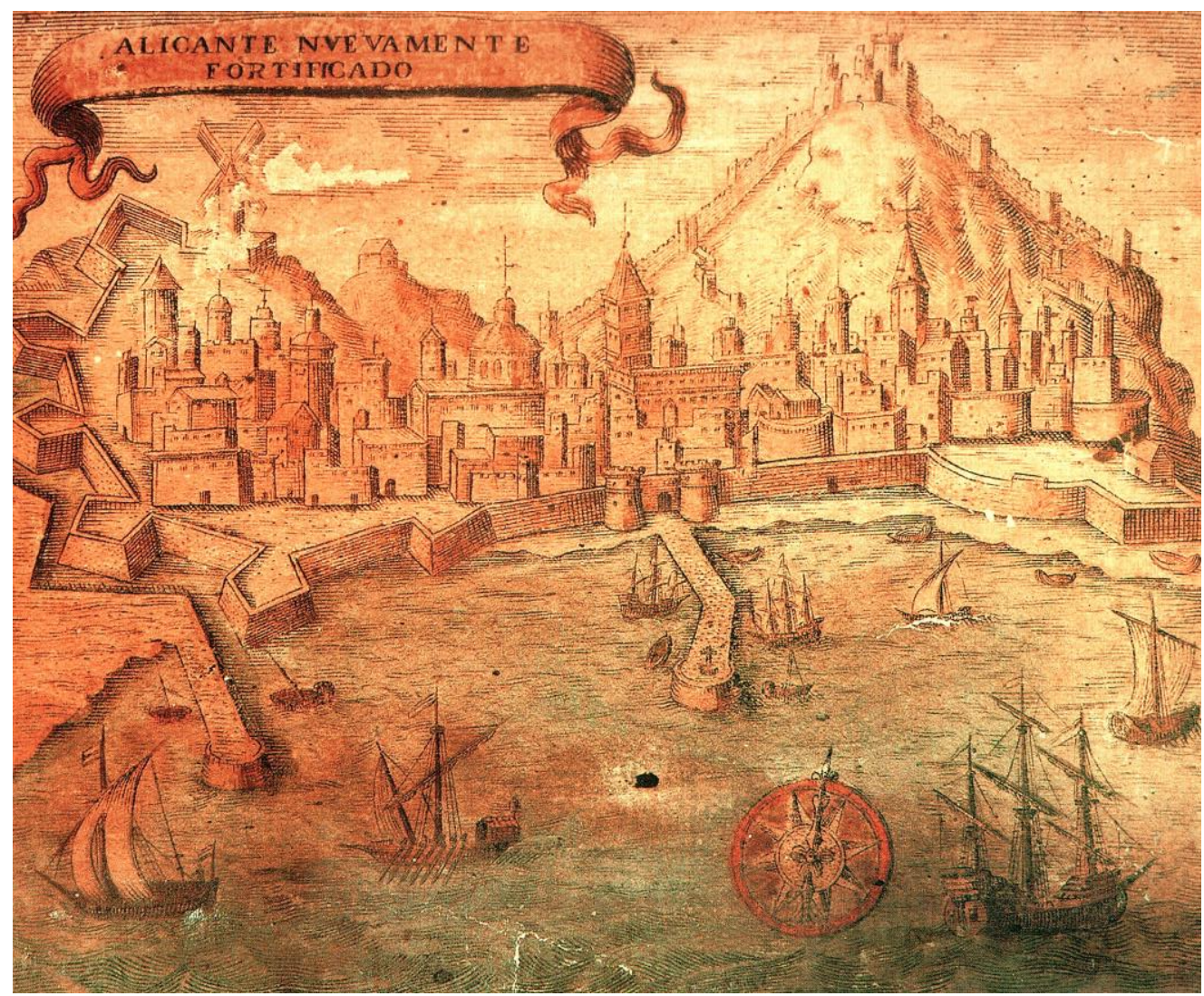

Nota: la figura procede del libro "Alicante, notas históricas, 1373-1800" de P. Orts y Bosch, Valencia, 1971. Fuente: Campos, 2007, pág. 63.

Habría de Llegar el siglo XIX y la Revolución Industrial para que el puerto de Alicante experimentara la primera gran transformación que lo adaptaría a los tiempos modernos. La introducción de la máquina de vapor y del hierro en la navegación hizo que se fuera pasando paulatinamente de los veleros a los barcos de vapor, con cascos y hélices de hierro, que consumían enormes cantidades de carbón, pero que contaban con un mayor tamaño y, por tanto, mayor capacidad. No solo se necesitó labores de dragado de las dársenas para dar cabida a los mayores calados de las embarcaciones, sino que hubo de aumentarse el espacio en tierra dedicado a la manipulación del volumen de mercancías, cada vez mayor. Hasta los muelles llegaron las instalaciones ferroviarias para facilitar el transporte terrestre, lo que incrementó aún más la acuciante necesidad de espacio en tierra. Además, fue en este siglo cuando la marina de guerra fue cediendo el testigo a la mercante, pasando los puertos españoles a depender del Ministerio de la Marina al de Fomento. Con este traspaso de competencias de las autoridades militares a las civiles, hubo que adaptar la mayoría de los enclaves portuarios a las nuevas necesidades que demandaba la creciente actividad comercial. Por todo ello, durante este siglo se realizaron obras de prolongación del muelle frente a la Puerta del Mar, muelle de Levante, y se inició la construcción del contramuelle, muelle de Poniente, separados unos 400 metros (Campos, 2007).

ACE, 14 (42) CC BY-ND 3.0 ES | UPC Barcelona, España | La génesis de los paseos litorales: el caso de la fachada marítima urbana de Alicante. DOI: http://dx.doi.org/10.5821/ace.14.42.8271 
Dentro de la colección de dibujos que el francés A. Guesdon realizó en torno a 1840 con el título España a vista de pájaro, existe uno dedicado a Alicante (Figura 3) que permite hacerse una idea de cómo era la ciudad a mediados del siglo XIX. Se distingue el muelle de Levante, el único en aquellos años previos a la construcción del de Poniente, con sus tinglados portuarios y un buen número de veleros fondeados en la dársena que no pueden acceder hasta el muelle para la carga y descarga de mercancías, de lo que se desprende las carencias del puerto decimonónico. A modo anecdótico, y como pincelada de lo que habría de venir, ya se aprecia algún barco de vapor en la rada.

No solo se identifican las construcciones emblemáticas, como el Castillo en lo alto del monte Benacantil, la cúpula azulada de la concatedral de San Nicolás o las dos torres del Ayuntamiento en la prolongación del muelle, sino que viene perfectamente representada la primera línea de costa, desde el baluarte de San Carlos - a la izquierda, en primer término - , pasando por la Puerta del Mar o del muelle, hasta llegar al baluarte de San Sebastián junto a la ladera del monte Benacantil. Se distinguen los edificios cuadrangulares de los mercados a la salida del dique, la primera línea de edificaciones, bastante homogénea entonces - o quizás representada de manera esquemática-, y el Malecón, sobre el que apenas unas décadas después se urbanizaría el Paseo de la Explanada.

Figura 3. Puerto de Alicante con importante volumen de embarcaciones. 1840

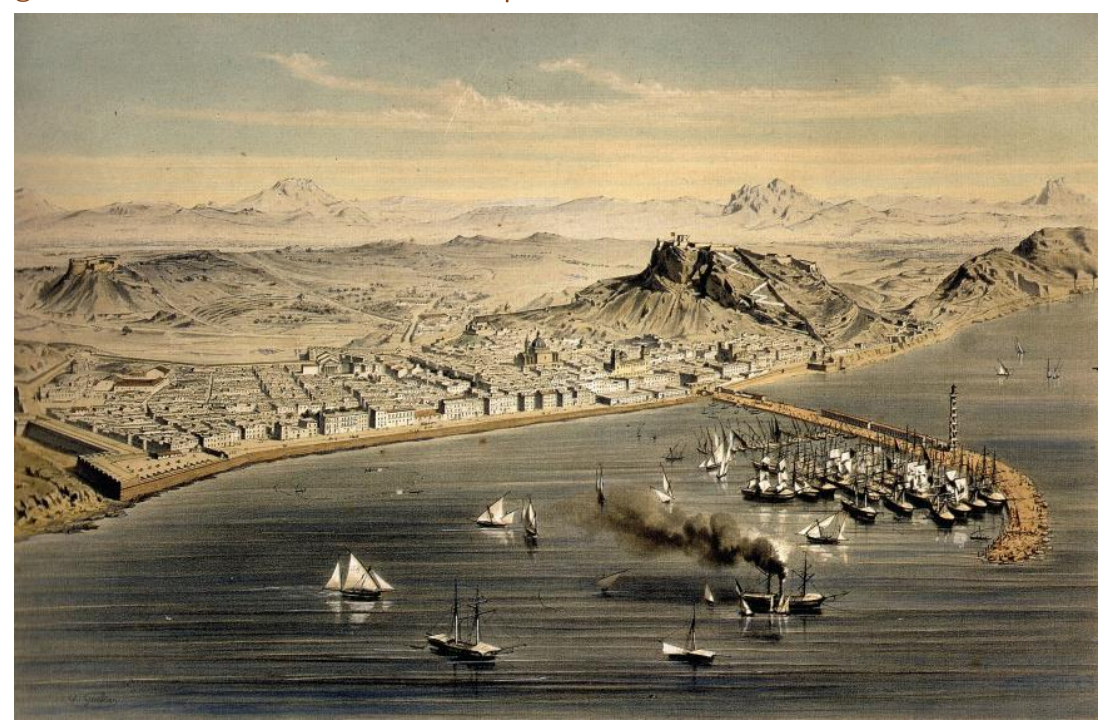

Notas: "Alicante". España a vista de pájaro. A. Guesdon. 1840. Litografía de la colección de la Autoridad Portuaria. Fuente: Campos, 2007, pág. 53.

Tras un período de obras y mejoras, en 1880 Alicante es declarado Puerto de Interés General de Primer Orden. Después del derribo de las murallas, la dársena se incorporó plenamente a la ciudad a la vez que el puerto cobraba identidad en sí mismo como elemento independiente. Maquinaria, locomotoras, grúas, tinglados y toda suerte de avances industriales fueron configurando un paisaje portuario urbano cuajado de actividad, promovida en gran parte por la exportación de vino.

Durante el siglo XX el puerto sufriría una gran transformación para aumentar su capacidad y mejorar los problemas de salubridad que provocaba que la dársena recogiera los desagües de las alcantarillas de la ciudad (Sánchez y Guardiola, 1894). Los primeros años se levantaron edificios singulares de estilo ecléctico - como el varadero o la lonja que, aunque con distinto uso, permanecen hoy - (Bevià y Varela, 1994), se prolongó y ensanchó el muelle de Levante y se originó un espolón junto al de Poniente, base del futuro ensanchamiento del puerto hacia el sur. En los años siguientes seguiría ganando en dimensiones (Figura 4, izda.). A partir de los años 50, los problemas consecuencia del 
desembarco de derivados del petróleo, que necesitaban medidas de seguridad especiales, así como el tráfico de mercancías a granel y el uso de contenedores como medio de transporte, crearon la necesidad de grandes superficies de carga y descarga. En los 70 se amplió hacia el sur, ganando un nuevo terreno al mar de 18000 metros cuadrados, que desde entonces no ha parado de crecer.

Figura 4. Fotografías aéreas del puerto de Alicante
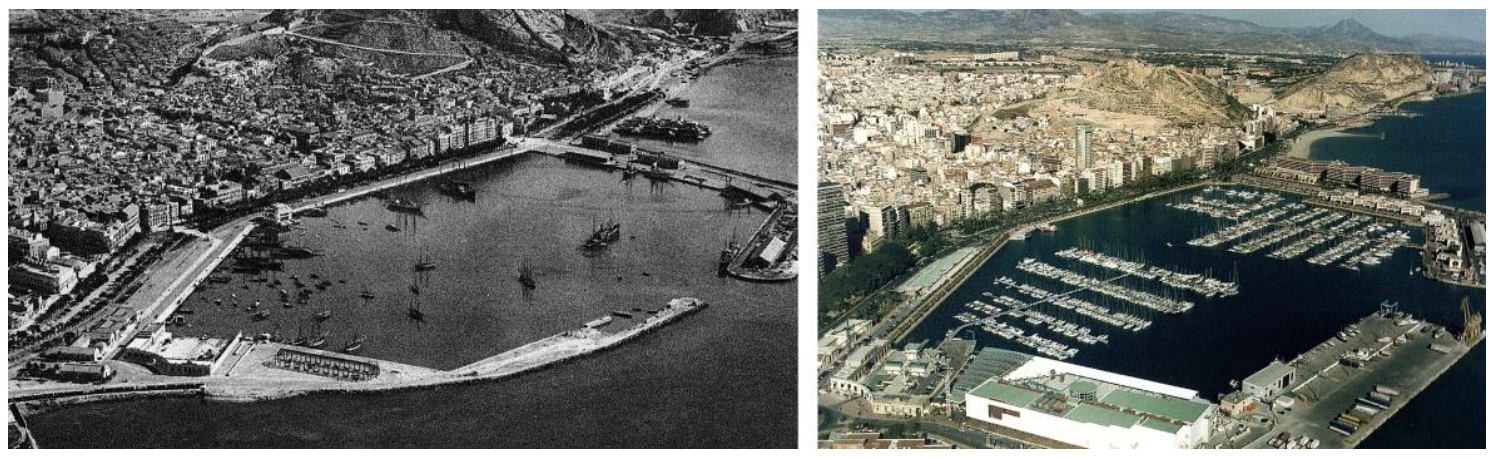

Notas: fotografía de 1940, donde se distinguen los tres paseos litorales: Canalejas, a izda., Explanada, delante de la dársena y Gómiz, frente a la playa (izda.); dársena ya reconvertida en marina deportiva, años 2000 (dcha.). Fuente: Campos, 2007, pág. 170 y 247.

Como consecuencia de la revolución en el transporte marítimo, las zonas portuarias de las ciudades costeras, como afirma R. Bruttomesso (2004, pág. 22), «han “liberado” las partes más estrechamente unidas al tejido urbano, dirigiéndose a la conquista de nuevos espacios, más periféricos y accesibles del hinterland». Así, diferencia tres directrices de actuación: "recomposición", "recalificación” y "recuperación". La "recomposición”, para dar sentido unitario a las diversas partes que componen las áreas portuarias e industriales; la "recalificación", con intervenciones sobre el waterfront que tienen en cuenta la revitalización de esas zonas urbanas, antaño portuarias, a menudo localizadas a escasa distancia del centro de la ciudad; y la "recuperación", con actuaciones sobre edificios singulares y estructuras existentes, a las que se les dota de una nueva función que contribuye a la regeneración de esas áreas abandonadas o deprimidas. Es en las zonas portuarias — waterfront "histórico" -, así como en las industriales, donde "se ha aplicado principalmente, aunque no exclusivamente, la importante y peculiar acción de renovación urbana que caracteriza a la ciudad post-industrial a finales del siglo XX» (Bruttomesso, 2004, pág. 25).

Esta estrategia de asignar un valor añadido al waterfront en el desarrollo del conjunto de la ciudad Lleva décadas produciéndose en Europa, donde son referentes los Docklands de Londres y el Port Vell de Barcelona, a los que han seguido otras ciudades inglesas (Liverpool, Glasgow, Cardiff), francesas (Le Havre, Dunkerke, St. Nazaire), alemanas (Hamburgo, Bremen, Kiel) y españolas (Valencia, Bilbao, Cádiz) (Bruttomesso, 2004). En Italia, además de las ciudades de Venecia, Nápoles o Trieste, destaca el caso de Génova en donde, a raíz de la Expo de 1992, se trató de recuperar las funciones urbanas del Puerto Antiguo de Génova, que dio lugar a dos propuestas del arquitecto Renzo Piano, en 2004 y 2014, para la reorganización general del frente marítimo de la ciudad (Gastaldi y Camerin, 2017). No obstante, es en Estados Unidos — con casos ejemplares como Baltimore y Boston- donde se ha consolidado un modelo de recalificación de las áreas de waterfront urbano-portuario, exportado al resto del mundo, concebido como impulsor de la renovación de estas zonas urbanas, a escala de toda la ciudad (Bruttomesso, 2004).

En el caso de Alicante, la remodelación más profunda de su waterfront llegó en 1992 con el Plan Especial del Puerto, con el que se trasladó toda actividad portuaria al sur de la ciudad. Se destinaron los muelles a nuevos espacios comerciales y de ocio - como el complejo Panoramis en el muelle de

ACE, 14 (42) CC BY-ND 3.0 ES | UPC Barcelona, España | La génesis de los paseos litorales: el caso de la fachada marítima urbana de Alicante. DOI: http://dx.doi.org/10.5821/ace.14.42.8271 
Poniente- y la dársena a marina deportiva para embarcaciones de recreo, a la vez que se unificaba todo el muelle de costa (Figura 4, dcha.) y se destinaban a otros usos edificios históricos portuarios. Se podría decir que en el relanzamiento del frente litoral de Alicante se han dado las directrices de "recalificación" de esas nuevas zonas ganadas para la ciudad y de "recuperación" de estructuras típicamente portuarias para otra función, no obstante, la labor de "recomposición”, es decir, de enlace de los distintos sectores que articulaban las zonas portuarias, dotándolas de un nuevo carácter inédito y atractivo, ha fracasado, dado que los locales comerciales y de ocio del complejo Panoramis componen un lugar poco frecuentado, a pesar de su emplazamiento privilegiado.

Desde que se inició el proceso de reconversión en los noventa, el puerto histórico se ha transformado en foco turístico y de ocio, donde se concentra la actividad hostelera combinada con actividades náuticas, como la Volvo Ocean Race, Vuelta al Mundo a Vela, de la que Alicante ha sido, desde 2008, cuatro veces puerto de salida. Siguiendo el ejemplo de ciudades italianas - como Génova, con la Expo de 1992, o Milán, con la Expo de 2015- y de ciudades españolas - como Sevilla, con la Expo de 1992, Barcelona, con las Olimpiadas de 1992 o Valencia, con la Copa América de Vela de 2007 a 2010 Alicante ha apostado por ser la sede de un gran evento deportivo como elemento activador de la mercadotecnia urbana, atrayendo nuevos recursos que incrementaran sus propios flujos culturales y turísticos y promocionaran la imagen de la ciudad. Estas actividades, si bien constituyen oportunidades (nuevas formas de coordinación entre diferentes actores, colaboración públicoprivada, etc.), conllevan riesgos (falta de participación ciudadana, corrupción, etc.) que pueden dar al traste con los procesos de regeneración urbana emprendidos (Gastaldi y Camerin, 2018).

Según un informe realizado por la consultora PwC, La Volvo Ocean Race 2017/2018 produjo 96,2 millones de Producto Interior Bruto, generando el equivalente a 1700 empleos anuales en España. El gasto de los 345602 espectadores desembolsado en Alicante ascendió a cerca de 62 millones de euros, consolidándose como el evento que más visitantes atrae a la Comunidad Valenciana. Alicante volverá a ser sede de la Vuelta al Mundo a Vela en las dos próximas ediciones (Martínez, 2018). No obstante, a pesar del impacto económico, a nivel urbanístico no se ha conseguido articular las zonas portuarias destinadas al evento con el centro urbano próximo y son poco frecuentadas por la población, más allá de los días propios del evento. En cualquier caso, la función de la fachada marítima de servir de entorno comercial del puerto, a finales del siglo XX, había llegado a su fin.

Desde el punto de vista morfológico, la actividad portuaria se desarrolló en el muelle, elemento perpendicular a la costa que se introducía hasta el centro neurálgico de Alicante a través de una puerta de la muralla - puerta del Mar —, recorriendo una vía prolongación del dique que desembocaba en el consistorio. En torno a este eje se desarrollaron los mercados, la aduana, consulados, etc. y, en suma, la estructura socioeconómica de la ciudad. Con el tiempo, la actividad portuaria se extendió hacia el sur, hasta conformar un nuevo muelle que cerraba la dársena —el de Poniente - a la vez que esa fachada marítima contigua se impregnaba de la tradición portuaria, con la instalación de viviendas-almacén de mercaderes y espacios de varadero. Se podría afirmar que siempre ha existido permeabilidad entre la ciudad y el puerto, apertura de la urbe hacia la creciente actividad de sus muelles, reflejada en el aumento de población, y, en definitiva, un indisoluble binomio puerto-ciudad.

\section{Las importantes transformaciones en el siglo XIX: la función lúdico- representativa}

La provincia de Alicante en la primera mitad del siglo XIX contaba con una serie de poblaciones industriales, era rica en materias primas y tenía una cierta actividad minera, además de un puerto con creciente actividad comercial. No obstante, adolecía de buenas comunicaciones terrestres. Como

ACE, 14 (42) CC BY-ND 3.0 ES | UPC Barcelona, España | La génesis de los paseos litorales: el caso de la fachada marítima urbana de Alicante. DOI: http://dx.doi.org/10.5821/ace.14.42.8271 
expone P. Madoz (1846), en toda la provincia de Alicante no había calzadas regulares, sino más bien de herradura y difíciles de transitar.

Su homónima capital era una ciudad de cierta entidad, con una población considerable -19 021 habitantes en 1845-, defendida por el castillo de Santa Bárbara, en aquellos años la plaza fuerte más importante del antiguo Reino de Valencia. Alicante, a las puertas de la era moderna, estaba en disposición de adaptarse a los cambios que la implantación de la red ferroviaria iba a suponer.

\subsection{La ordenación de la ciudad y el derribo de las murallas}

A principios del siglo XIX la población vivía hacinada con apenas 31,45 $\mathrm{m}^{2}$ por habitante, que descendieron hasta $15 \mathrm{~m}^{2}$ en 1857, convirtiendo la situación en insostenible (Giménez et al., 1985). La falta de salubridad e higiene, la insuficiente ventilación y soleamiento de las viviendas, la escasez de agua potable, etc., constituyeron el caldo de cultivo para la propagación de pandemias que asolaron la población. Poner solución al problema era prioritario y para ello se iniciaron los primeros trabajos de ordenación de la urbe, como el trazado de alineaciones de 1815 (Viravens y Pastor, 1876), o el Plano Geométrico de 1849, primer instrumento de intervención urbanística en el conjunto de la ciudad. El autor de dicho plano, E. Jover, propuso que en la línea de la costa se ganara terreno al mar para regularizarla y, en ese nuevo espacio, edificar dos nuevas hileras de manzana regulares. Por suerte, finalmente se levantó una sola fila y en las manzanas no realizadas se urbanizó tiempo después el actual paseo de la Explanada (Domingo, 2014).

La primera destrucción de parte de las murallas se dio en 1820. Le siguieron derribos parciales de puertas de entrada a la ciudad, pero la supresión de la totalidad de las murallas inició un litigio entre el Ayuntamiento y el Ministerio de la Guerra, que desaprobaba que Alicante dejara de ser plaza fuerte. Finalmente, mediante una Real Orden de 1858, la reina Isabel II autorizó el derribo de las murallas, determinando que Alicante dejara de ser plaza de guerra (Rosser, 1990). El proceso de eliminación de muros y elementos defensivos fue largo y complejo, con una pugna entre la institución militar y la municipal por la propiedad que las defensas ocupaban. Duraría veinticinco años, dándose por concluido en 1884 aunque todavía quedaba algún resto.

Liberada de corsés, la ciudad estaba lista para acometer su proceso de expansión, que se materializaría con la Ley de Ensanche, promulgada en Alicante en 1896. De hecho, emprender la ordenación de la extensión de la ciudad era cuestión urgente dado que a lo largo del siglo XIX se había triplicado el perímetro de su recinto amurallado, pasando de tener 2946 edificios en 1860 a 5710 en 1900 (Alonso et al., 1990). El plano de Ensanche aprobado en 1890, trazado por J. Guardiola Picó y rectificado por J. González Altés, proyectaba la formación del paseo de la Explanada en los terrenos del Malecón ganados al mar. Este nuevo espacio público para la ciudad sustituía a las manzanas rectangulares frente al mar, propuestas inicialmente en el plano geométrico de 1853. En esos años el paseo tenía menor longitud que en la actualidad puesto que los edificios del mercado lo limitaban al este, y el trazado del ferrocarril al oeste, aunque pronto sería desplazado al extrarradio de la ciudad.

El plano de Anteproyecto de Ensanche de 1889 (Figura 5) es interesante porque nos permite identificar los cambios morfológicos que se dieron en esos años, así como conocer el estado de la ciudad a finales del siglo XIX: la trama existente - manzanas coloreadas en oscuro- y la proyectada por el Ensanche - manzanas dispuestas ortogonalmente en tonos claros-. Se observa, a la derecha, el monte Benacantil, con el castillo en su cima, y en torno a él una trama urbana irregular, adaptándose a la orografía del terreno, correspondiente al asentamiento histórico originario de la urbe. Desde allí, la ciudad se fue extendiendo hacia el llano - al suroeste, a la izquierda del planosiguiendo la línea litoral, y esa misma tendencia la planteaba el propio Plan de Ensanche representado. Respecto al puerto, aparecen grafiados los dos muelles: el de Levante, a la derecha - 


\section{ACE Architecture, City and Environment}

origen del puerto - y el de Poniente, a la izquierda — construido posteriormente-. Con respecto a la fachada marítima, dentro de la dársena del puerto aparece en primer término: ya urbanizado, el paseo de La Explanada - partiendo de los dos edificios cuadrangulares del mercado, junto al muelle de Levante - enmarcando la trama de la ciudad consolidada; y a la izquierda, el parque de Canalejas todavía un proyecto - sirviendo de frente marítimo a la trama de Ensanche propuesta. Ambos bulevares se articulan como un elemento continuo que configura la fachada litoral de la ciudad en su encuentro con el mar. Al otro lado del muelle de Levante - a la derecha de la figura -, la playa del Postiguet, que ya albergaba las instalaciones estacionales de los balnearios y donde, a los pocos años, se urbanizaría el tercer paseo, el de Gómiz, completando el trío de bulevares costeros que conforman en la actualidad el frente litoral alicantino.

Figura 5. Plano de Anteproyecto de Ensanche de Alicante. J. Guardiola Picó. 1889

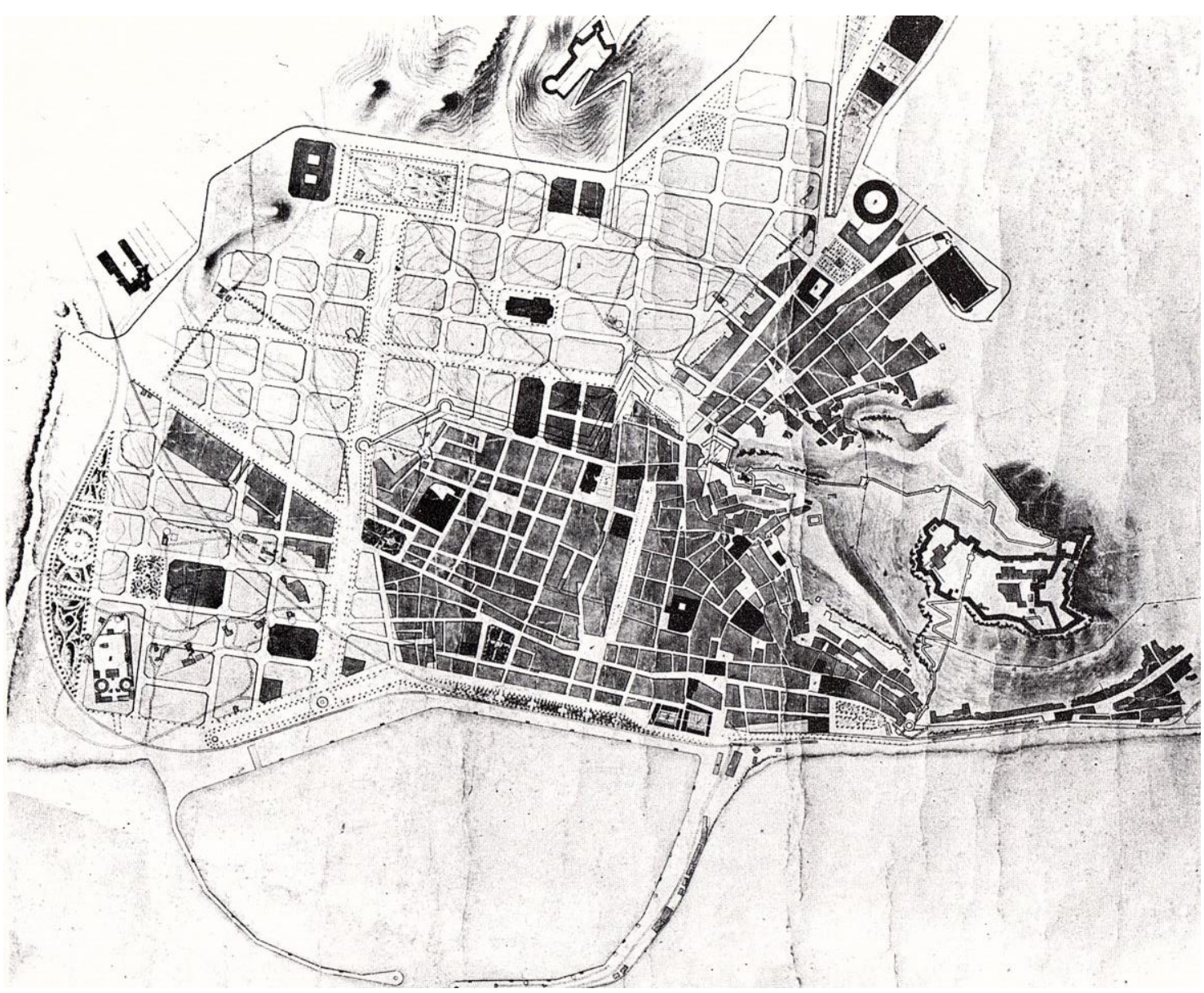

Fuente: Calduch y Varela, 1979, pág. 21.

La ciudad, tal y como se aprecia, distaba mucho de la urbe amurallada representada apenas unas décadas antes por Guesdon (Figura 3). De unas murallas costeras y un sucio malecón junto al puerto, se había pasado a un bulevar arbolado en el encuentro de la ciudad con el mar, que en los años sucesivos se prolongaría hacia el norte y hacia el sur, como un nuevo eje vertebrador de la ciudad.

El Plan de Ensanche de Alicante no se acometió como hubiese sido deseable ni se obtuvo el beneficio para la ciudad esperado (Ramos, 1984). La conciencia crítica de urbanistas, como J. Guardiola Picó, y de médicos, como E. Manero Mollá, que trataron de implantar las corrientes higienistas en aras de la 
mejora de las condiciones higiénico-sanitarias del Alicante decimonónico, no fue suficiente. La lentitud en su tramitación, la escasa implicación de las autoridades, la enajenación a la propiedad privada de terrenos donde antes había elementos defensivos, etc., son algunas de las razones a las que se achacó entonces la escasa relevancia del Ensanche. Seguramente motivado por la falta de interés por Alicante por parte del Gobierno central cuando ésta dejó de ser plaza fuerte y por la falta de iniciativa de las autoridades locales, se impidió que se acometieran las reformas urbanas profundas necesarias que el Higienismo propugnaba y que la ciudad tanto necesitaba (Ponce y Dávila, 1998). Afortunadamente, los paseos litorales fueron excepción a esta norma y, gracias a esa idea inicial de sus creadores de urbanizar una fachada monumental continua -al estilo de otras ciudades europeas costeras - , se consolidaron como espacios públicos de éxito en los que ver y dejarse ver y como enclave elegido por buena parte de la burguesía local para edificar sus residencias en las que mostrar su poderío económico. Aunque en varias avenidas principales de la zona de ampliación interior de la ciudad se levantaron edificios burgueses señoriales de cierta entidad, el foco urbano se había trasladado junto al mar, en parte motivado por la actividad de los balnearios, como veremos a continuación. Se podría afirmar que el par Ensanche-Modernismo, característico en otras latitudes, no se dio del todo en Alicante.

\subsection{La llegada del ferrocarril a la costa}

La Revolución Industrial, iniciada a finales del siglo XVIII y que se desarrollaría a lo largo del XIX, trajo consigo la invención de la máquina de vapor que daría lugar al ferrocarril. Inaugurada en 1830, la primera línea ferroviaria, que discurría entre Liverpool y Manchester (Reino Unido), fue el germen de un profundo cambio en la red de comunicaciones que facilitaría el rápido desarrollo en la industria y que daría un giro radical al sistema económico, político y social establecido. El primer trayecto en tren en suelo español fue el que enlazaba las ciudades de Barcelona y Mataró, inaugurado en 1848. Seguidamente, llegaría el de Madrid-Aranjuez, como un primer tramo de la línea que pretendía unir la capital con la costa, en concreto con Alicante.

A las puertas de la era industrializada, Alicante contaba con una actividad económica de cierta relevancia, pero, a pesar de tener un importante puerto comercial de primera clase, carecía de una buena comunicación con el interior de la península. La opción más ventajosa, frente a otras urbes, como Valencia, Cartagena o Santander, era conectar Madrid con el puerto de Alicante debido en gran medida a la suave orografía del terreno y a la escasez de obstáculos que salvar del recorrido. Tras varios proyectos e iniciativas fallidas, finalmente en enero de 1858 llegaba a Alicante el primer tren procedente de Madrid. Unos meses después, como la magnitud de los acontecimientos requería, el 25 de mayo de 1858 la Reina Isabel II de Borbón inauguró oficialmente en Alicante la primera línea ferroviaria que unía la capital con el mar. Este hecho supuso la entrada de Alicante en la modernidad y el inicio de una nueva etapa de tránsito de personas y mercancías con el interior de la península que habría de cambiar definitivamente el curso de la historia de la ciudad y de su fachada marítima.

Tan solo unos años después de la llegada del primer tren a Alicante se realizó un ramal que conectaba con el puerto la estación término, situada en el interior donde permanece hoy, entonces extrarradio. Este sería el origen de la compleja red logística del puerto, un anillo ferroviario que envolvía la dársena, enlazándolo con las nuevas estaciones de ferrocarril y con las carreteras de Alicante (Aguilar, 2008). Se trataba de incrementar la eficacia del transporte marítimo, facilitando el tránsito de mercancías. Unas décadas después de la primera línea férrea se inauguraba el tren de Murcia, también con su conexión hasta el puerto, mejorando las conexiones de la ciudad hacia el sur. El entramado ferroviario que llegaba hasta el puerto dio lugar a la aparición de dos estaciones junto a la línea de la costa, edificios que a día de hoy siguen en pie, aunque con otros usos: la estación de Murcia, hacia el sur, y la estación de la Marina, hacia el norte. Estas dos estaciones sirven para delimitar la fachada marítima del núcleo urbano histórico de Alicante, ámbito de estudio de esta investigación. La ubicación de las 
mismas no es arbitraria dado que en aquellos años, como ocurriría en poblaciones litorales vecinas como Cartagena, las estaciones ferroviarias se construían en el borde edificado, es decir, en el Ensanche de la ciudad, buscando la economía de medios, la facilidad de su trazado y la cercanía al enclave portuario (Martínez, 2015).

La aparición del ferrocarril en el entorno urbano, desplazando al carro para el transporte terrestre, propició que hubiera de reordenarse las ciudades, y los enclaves portuarios a los que daba servicio, para dar cabida a la estructura que el ferrocarril implicaba. Escribía el arquitecto municipal J. Guardiola Picó: "La construcción de la vía férrea de Madrid y la construcción del puerto, obligaron á transformar parte interior de la ciudad; [...]”. Sin embargo, lejos de ser un estorbo para el normal desarrollo de la vida de la ciudad, la presencia del tren se percibía casi como un elemento paisajístico y como símbolo de modernidad: "Recordemos qué era el antiguo Malecón y veámoslo hoy convertido en el sitio más ameno, más higiénico y más hermoso de la ciudad, donde no hay forastero que no contemple con admiración aquel pintoresco jardín, donde crece el pino al lado de la palmera a orillas del mar, y desde donde se ve a la vez que el buque de vapor surcando las rizadas olas, correr la locomotora sobre cintas de hierro que serpentean junto a un bosque de palmeras y frente a una cortina de suntuosos edificios" (Guardiola, 1895, pág. 76-79).

Desde finales del siglo XIX hasta bien entrado el XX se dio prioridad a las comunicaciones ferroviarias, hasta el punto de introducirlo por la costa hasta el centro neurálgico de la ciudad (Figura 6, izda.). No es difícil componer la imagen del entramado de vías de tren, ramales, locomotoras, vagones de mercancías, apeaderos, estaciones, etc., que en aquellos años discurrían a lo largo de la fachada marítima, desde la estación de Murcia hasta la playa del Postiguet. Habrían de pasar varias décadas para que la red de ferrocarril fuera desapareciendo del frente marítimo, dando paso a un espacio ganado para la ciudad, como lugar de recreo y disfrute de los visitantes que el turismo habría de traer. Todos esos edificios y tinglados se incorporaron al paisaje urbano de la fachada costera, y alguno de ellos todavía permanece como testimonio de la época de esplendor de la máquina de vapor.

Un hito tan importante como fue la llegada del ferrocarril, no solo se produjo en época de transformaciones, sino que el hecho en sí mismo modificó la morfología de la urbe y de su fachada marítima. Por un lado, hubo que abrir brechas en la obsoleta muralla para permitir el trazado de las vías y las nuevas estaciones ferroviarias se convirtieron en puntos de atracción en torno a los cuales se conformaron nuevos barrios y establecimientos hosteleros para dar servicio a los viajeros, como ocurrió en el frente costero. Por otro lado, surgieron nuevas fábricas y almacenes en los alrededores para dar servicio al puerto, porque allí donde llegara el tren la mejora de las comunicaciones y la aparición de nuevos caminos y carreteras estaba asegurada.

Figura 6. El tren y los balnearios
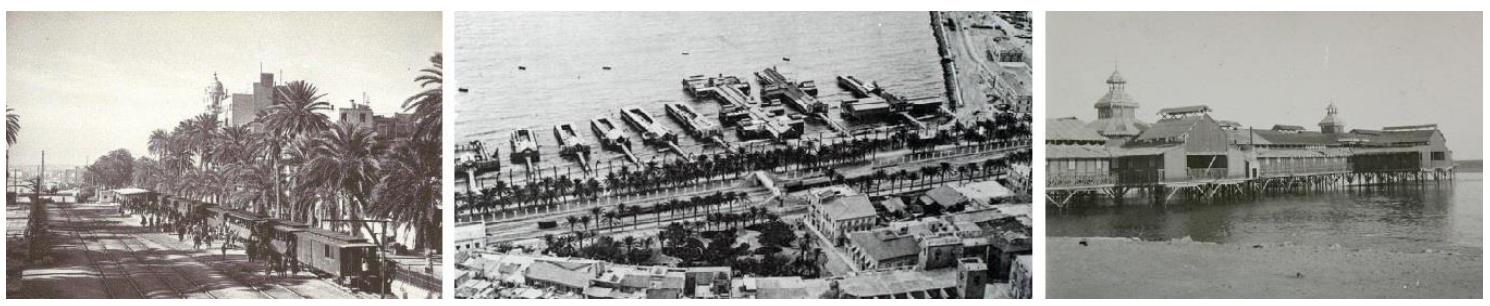

Notas: convoy de ferrocarriles por la costa, 1947 (izda.); balnearios en la playa del Postiguet, 1915 (centro); balneario, 1920 (dcha.). Fuente: Archivo Municipal de Alicante. 


\subsection{El auge de la moda de los baños de mar}

El uso del agua como poderoso medio terapéutico es un factor común a las culturas ancestrales. A finales del siglo XVIII, se instauró la moda entre las clases altas inglesas de que tomar los baños era saludable y en 1823 se abría al público en Brighton el Chain Pier, plataforma que se adentraba en el mar y que daría lugar a la aparición de las casas-balneario. En España, promovidos por la realeza y la burguesía de mediados del siglo XIX, los baños de mar se convirtieron en un hábito de salud identificado con las clases sociales de alto poder adquisitivo (Melgosa, 2000), que adoptarían la costumbre de cambiar de residencia durante la época estival para trasladarse al litoral. Todo ello daría lugar a un modelo de urbanización característico, el de ciudad-balneario, formada por largos paseos marítimos, casas de baños, hoteles, cafeterías, casinos, etc., para dar servicio a los visitantes que llegaban a tomar las aguas, que en nuestro caso de estudio se materializó en la fachada marítima.

La moda de los baños de mar, que debían tomarse bajo prescripción médica (Vera, 1987), la traerían a Alicante los comerciantes europeos, sobre todo franceses, en las primeras décadas del siglo XIX. De 1834 son los primeros pabellones instalados en el puerto - que posteriormente se trasladarían a la contigua playa del Postiguet - pero no será hasta unas décadas después, a partir de la llegada del primer ferrocarril a Alicante procedente de Madrid en 1858, cuando los baños de mar se popularizaron gracias a la apertura de la costa a los habitantes del interior. De hecho, se podría afirmar que la inauguración de la primera línea ferroviaria con la costa supuso el inicio del turismo en la zona y la consideración del mismo como posible fuente de riqueza.

En 1893 se inauguró en la línea Madrid-Alicante el popularmente conocido como tren botijo. Se trataba de un tren turístico de bajo coste que permitía a los viajeros, a precios asequibles, estancias de doce días en Alicante para tomar los baños. Era utilizado mayoritariamente por las clases populares, que se desplazaban hasta la playa en los meses de verano portando un botijo — de ahí el apelativo- en su equipaje para soportar las 14 horas de trayecto. "De los baños de mar pueden disfrutar hasta las personas menos acomodadas, contribuyendo en gran parte la baratura de los trenes" decía J. Aller y Vicente (1900, pág. 13), a la vez que expresaba el ambiente festivo con que se vivía el evento. Este tipo de tren funcionó hasta 1917 con una media de 30000 viajeros por año.

En esta época, las arquitecturas efímeras de los balnearios poblaban la fachada marítima. Por lo general, las instalaciones se componían de casetas de madera o lona para el cambio de vestuario y balnearios sobre pilotes, a modo de plataformas enclavadas en la arena sobre el mar (Figura 6, centro y dcha.). Solían tener planta rectangular y albergaban un salón central, que recibía luz por las fachadas y tragaluces, rodeado de galerías exteriores a modo de balcones. En el interior había numerosas casetas que comunicaban directamente con el mar mediante peldaños. Ofrecían al bañista restaurante, duchas, espacios a la sombra, tienda de artículos e incluso una cuerda que se adentraba en el agua para facilitar la sujeción de aquellos que no sabían nadar (Grao-Gil, 2020). Llegó a haber once establecimientos al mismo tiempo, tres de ellos de carácter permanente y desmontables los demás, retirados cuando acababa la temporada de baños (Vera, 1987).

Se trataba de componer un espacio lúdico, atractivo para el bañista, que invitara al descanso y a las relaciones sociales. Si bien el fin primero era el fortalecimiento de la salud, los baños de mar propiciaban una serie de actividades de ocio que se desarrollaban en paralelo para hacer más placentera la estancia de sus usuarios. Una vez acabada la hora del baño, en los agradables paseos de reciente creación en el entorno de los balnearios _Explanada, Canalejas y Gómiz_ proliferaban actividades de entretenimiento. Durante la época estival, ferias, teatros, cines de verano, conciertos en el templete, etc., se sucedían como parte de la oferta turística que la ciudad proporcionaba. 
No es casual, por tanto, que en estos años la fachada marítima contara con diversos hoteles, restaurantes y cafeterías para cubrir esa demanda que la nueva actividad comercial y social reclamaba. La función lúdico-representativa del frente costero alicantino no había hecho más que empezar.

A partir de los años treinta del pasado siglo, debido al cambio en los hábitos sociales establecidos y a la aparición de nuevas técnicas medicinales, los baños de mar entraron en decadencia. La irrupción del automóvil, y su posterior popularización, jugó un importante papel. El acceso a las playas, sin depender de hasta dónde les llevara el tren, amplió el abanico de posibilidades a la hora de elegir destino vacacional.

Tras el paréntesis de la Guerra Civil y los difíciles años de posguerra, el turismo de balnearios dio paso al de sol y playa, extendido a lo largo de la costa. En 1969 fueron derribados los dos últimos balnearios que permanecían en pie en Alicante, dando por concluida una etapa que duraría más de un siglo.

A pesar de lo efímero de su arquitectura, las casas de baños moldearon la fachada marítima modificando su morfología para siempre. Y es que, debido al fenómeno de la balneoterapia, la ciudad hizo un ejercicio de adecuación de su frente litoral reordenándolo y adaptando su función a lo que la sociedad de entonces demandaba. La fachada marítima se convirtió en lugar de residencia de las clases altas y de alojamiento de turistas, que pasaban su tiempo libre en largos paseos junto al mar. El foco de atracción de visitantes y lugareños se trasladó del núcleo histórico tradicional hacia el Ensanche y la costa, y allí permanecería hasta que unas décadas después entrara en una cierta decadencia.

\section{La urbanización de los paseos litorales}

Tras las importantes transformaciones acaecidas durante la segunda mitad del siglo XIX, con la llegada del ferrocarril, el derribo de las murallas y elementos defensivos, el inicio de la ordenación de la ciudad y la aparición del fenómeno del turismo, Alicante se encontraba en pleno proceso de asimilación de los cambios y de adaptación de su morfología urbana a las nuevas necesidades surgidas (Jaén et al., 1999). Dentro de este contexto, la urbanización de los paseos litorales jugó un importante papel.

Herederos de las alamedas de épocas ilustradas y de la ideología higienista, eran conocidos bajo el nombre de jardín-bulevar, muy en boga en siglo XIX, con esa forma burguesa de concebir la ciudad con espacios públicos ajardinados, saludables, higiénicos y donde poder disfrutar de la naturaleza, al alcance de toda la población (Jaén y Gutiérrez, 2014).

Se distinguen tres paseos principales dentro de la fachada marítima: el protagonista indiscutible es la Explanada, tramo central y primero que se urbanizó; el Paseo de Canalejas, surgido años después como prolongación hacia el sur del anterior y continuador del esquema de fachada monumental; y el Paseo de Gómiz, hacia el norte, junto a la playa del Postiguet, testigo del auge de los baños de mar y de la posterior explosión del turismo de sol.

A modo de resumen del contenido expuesto en este apartado, en relación a los tres paseos litorales alicantinos analizados, se introduce la Tabla 1, comparativa de las características principales de los mismos.

ACE, 14 (42) CC BY-ND 3.0 ES | UPC Barcelona, España | La génesis de los paseos litorales: el caso de la fachada marítima urbana de Alicante. DOI: http://dx.doi.org/10.5821/ace.14.42.8271 
Tabla 1. Los paseos litorales urbanos de Alicante. Génesis y transformaciones principales

\begin{tabular}{|c|c|c|c|}
\hline & Paseo de la Explanada & Parque de Canalejas & Paseo de Gómiz \\
\hline Emplazamiento & $\begin{array}{l}\text { Frente a la dársena portuaria } \\
\text { histórica. Fachada marítima } \\
\text { urbana por excelencia (entre } \\
\text { monumento a Canalejas y } \\
\text { plaza de la Puerta del Mar). }\end{array}$ & $\begin{array}{l}\text { Fachada marítima urbana } \\
\text { desde la Explanada hacia el } \\
\text { sur (delante de la actual } \\
\text { avda. Dr. Ramón y Cajal). }\end{array}$ & $\begin{array}{l}\text { Marco de la playa urbana } \\
\text { de Alicante, el Postiguet. }\end{array}$ \\
\hline Longitud & $570 \mathrm{~m}$ & $540 \mathrm{~m}$ & $830 \mathrm{~m}$ \\
\hline Precedentes & $\begin{array}{l}\text { Murallas defensivas costeras } \\
\text { y Malecón (1833) tras el } \\
\text { derribo de éstas. }\end{array}$ & $\begin{array}{l}\text { Baluarte de San Carlos y } \\
\text { Varadero (reparación barcos } \\
\text { y acopio de mercancías). }\end{array}$ & $\begin{array}{l}\text { Playa junto al barrio de } \\
\text { pescadores Raval Roig } \\
\text { donde varaban sus barcas. }\end{array}$ \\
\hline Origen & $\begin{array}{l}\text { Acondicionamiento del } \\
\text { Malecón como bulevar. }\end{array}$ & $\begin{array}{l}\text { Prolongación de la } \\
\text { Explanada hacia el sur. }\end{array}$ & $\begin{array}{l}\text { Prolongación de la } \\
\text { Explanada hacia el norte. }\end{array}$ \\
\hline $\begin{array}{l}\text { Proceso de } \\
\text { configuración }\end{array}$ & $\begin{array}{l}\text { Las originarias viviendas- } \\
\text { almacén de comerciantes } \\
\text { junto al puerto, durante s. } \\
\text { XIX, se transformaron en } \\
\text { residencias burguesas. }\end{array}$ & $\begin{array}{l}\text { Almacenes y locales de } \\
\text { exportación ligados al } \\
\text { varadero derivaron en } \\
\text { edificios residenciales, a } \\
\text { semejanza de la Explanada. }\end{array}$ & $\begin{array}{l}\text { El auge de los balnearios y } \\
\text { el éxito de la Explanada a } \\
\text { finales del s. XIX } \\
\text { promovieron la } \\
\text { urbanización del paseo. }\end{array}$ \\
\hline Urbanización & 1868 & 1891 & 1890 \\
\hline Estructura & $\begin{array}{l}\text { Bulevar peatonal con hileras } \\
\text { de palmeras paralelas a la } \\
\text { costa, en corredor central y } \\
\text { dos laterales, con circulación } \\
\text { rodada en el lado del puerto. }\end{array}$ & $\begin{array}{l}\text { Plataforma central elevada } \\
\text { con hileras de árboles en } \\
\text { paralelo a la costa, fuentes y } \\
\text { esculturas, y con circulación } \\
\text { perimetral. }\end{array}$ & $\begin{array}{l}\text { Paseo marítimo con hileras } \\
\text { de palmeras junto a la } \\
\text { playa. Circulación rodada } \\
\text { longitudinal junto al paseo. }\end{array}$ \\
\hline $\begin{array}{l}\text { Cambios } \\
\text { importantes }\end{array}$ & $\begin{array}{l}\text { 1910: derribo del mercado y } \\
\text { prolongación del paseo } \\
\text { 1955: pavimento mosaico } \\
\text { 1992: cambio circulaciones. }\end{array}$ & $\begin{array}{l}\text { 1908: conclusión del paseo } \\
\text { 1992: cambio de las } \\
\text { circulaciones perimetrales y } \\
\text { plataformas adyacentes. }\end{array}$ & $\begin{array}{l}\text { Finales 60: derribo últimos } \\
\text { balnearios, eliminación de } \\
\text { vías férreas, prolongación y } \\
\text { pavimentación del paseo. }\end{array}$ \\
\hline $\begin{array}{l}\text { Configuración } \\
\text { actual }\end{array}$ & $\begin{array}{l}\text { Paseo de palmeras junto al } \\
\text { puerto de recreo, lugar } \\
\text { emblemático de la ciudad. }\end{array}$ & $\begin{array}{l}\text { Zona verde de gran entidad, } \\
\text { con configuración de parque } \\
\text { urbano. }\end{array}$ & $\begin{array}{l}\text { Paseo marítimo paralelo a } \\
\text { la costa, separado de la N- } \\
332 \text { por vegetación y vial. }\end{array}$ \\
\hline
\end{tabular}

Fuente: elaboración propia a partir de la información histórica disponible. Año 2019.

\subsection{El paseo de la Explanada}

Conocido en sus inicios como Malecón, posteriormente, cuando ya fue urbanizado pasó a llamarse Paseo de los Mártires y finalmente Explanada de España, aunque popularmente se le conoce como La Explanada. Se trata de un paseo litoral de 570 metros de longitud, que se extiende siguiendo la línea de la costa, desde el monumento a Canalejas - aproximadamente donde antaño estuvo el baluarte de San Carlos - hasta la plaza de la Puerta del Mar. Plataforma ganada al mar, como proyecto no se materializaría hasta 1833, tras realizar el derribo de las murallas de la costa y el uso de los escombros resultantes para la nivelación de los terrenos. En esta nueva superficie se crearon dos calles paralelas a la costa: la de San Fernando, por el interior, y el Malecón, frente al mar.

Es probable que el origen mercantil de la burguesía local, muy ligada al puerto, hiciera que abandonaran el antiguo recinto urbano del siglo XVI para edificar sus residencias en el Ensanche y en los nuevos terrenos del Malecón, junto al muelle. Las viviendas levantadas en la primera mitad del siglo XIX eran de estructura sencilla, de tres plantas a lo sumo, con ornamentación escueta de corte clasicista (Aldana, 2004). Algunas de ellas eran vivienda-almacén, con acceso desde la calle San Fernando, ya que todavía por entonces no estaba urbanizado el Malecón, que era más bien un espacio sucio y residual ligado a las labores comerciales del puerto y del mercado de abastos próximo (Llorca, 1990). Varios de estos locales de comerciantes, con acceso desde la calle San Fernando, se ampliaron algunos pisos para hacer viviendas con fachada al nuevo Malecón, cuando las alineaciones lo permitieron.

La sobriedad en las fachadas de los años de la primera mitad del siglo XIX dio paso, sin abandonar el clasicismo, a una mayor ornamentación con profusión de elementos decorativos en la segunda mitad, 
como una forma de mejorar su propiedad haciendo alarde a través de la arquitectura de la prosperidad de su negocio. Se comenzó a dar similar tratamiento a las fachadas de ambas calles, San Fernando y Malecón, y la monumentalidad fue en aumento, como signo exterior de la importancia social de sus moradores. Se instaló la institución del Casino de Alicante - que se conserva parcialmente-, se abrieron hoteles de cierto renombre y, así, parcela a parcela, se fue generando la nueva fachada al Malecón, es decir, el nuevo frente marítimo de la ciudad.

En el año 1868 se concluyó el primer proceso urbanizador y de embellecimiento del Malecón. Este paseo es la obra urbanística más emblemática dentro de la corriente higienista que su creador, el arquitecto J. Guardiola Picó, promulgaba (1895): “El Ayuntamiento debería buscar los medios e influencias para conseguir la propiedad del Paseo de los Mártires y su prolongación por la Explanada de España - actual Parque de Canalejas-. Además, prolongar hacia el Este y el Oeste, consiguiendo lo que podríamos llamar paseo Marítimo, protegido de los vientos del Norte y muy higiénico". En los años sucesivos se materializaría esta idea con la creación de los dos nuevos bulevares, Canalejas y Gómiz, que veremos a continuación.

En un principio, el paseo tenía menor longitud dado que se hallaba limitado en su lado este por los dos edificios del mercado de abastos, que sobresalían notablemente con respecto a la alineación del resto de la Explanada (Zaragoza, 2007). En estado ruinoso, se autorizó su derribo en 1910, se trasladó el mercado a un nuevo emplazamiento y se prolongó el paseo, adquiriendo las dimensiones que conocemos hoy. En el solar resultante algunos años después se levantó la Casa Carbonell, edificio residencial emblemático de la fachada marítima (Figura 7, dcha.). En esos años se comenzó una profunda reforma del puerto, iniciando la construcción del muelle de Poniente y prolongando el de Levante, y se llegó a un acuerdo entre las autoridades municipales y portuarias para trabajar conjuntamente en la reordenación de los paseos públicos y los servicios del puerto.

Figura 7. Paseo de la Explanada
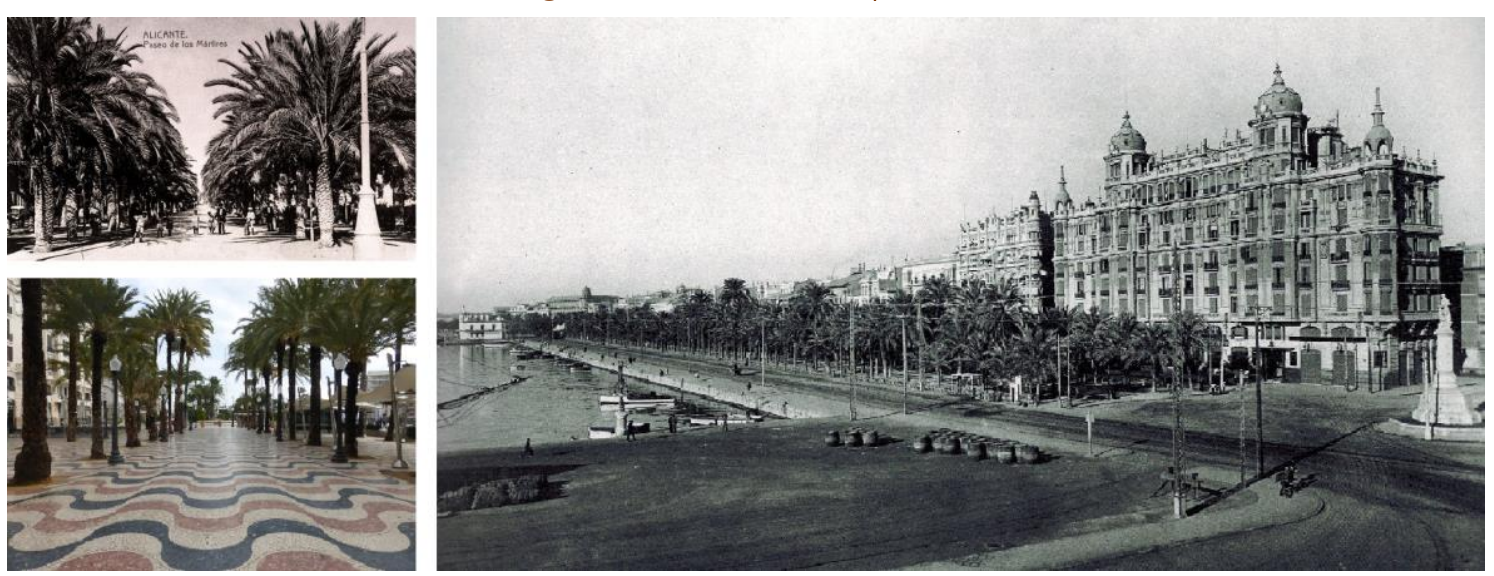

Notas: año 1900 aprox. (izda. sup.); año 2019 (izda. inf.); vista de la Explanada desde el inicio del muelle de Levante, con la Casa Carbonell en primer término y el desaparecido monumento a los mártires de la libertad de la plaza del Mar, año 1926 (dcha.). Fuente: Archivo Municipal (izda. sup.), autora (izda. inf.) y Campos, 2007, pág. 168 (dcha.).

Durante la Guerra Civil española, que asoló el país entre los años 1936 y 1939, Alicante fue especialmente castigada, a pesar de tratarse de una zona de retaguardia. La provincia fue morada del último gobierno republicano en suelo español, por ser enclave portuario alejado de los frentes de batalla. Alicante también fue destino de acogida de refugiados y último puerto de salida para su evacuación (Olmo, 2016). Tan solo dos días después de que zarpara del puerto alicantino el último barco con rumbo al exilio y que las tropas nacionales entraran en la ciudad, se anunció el fin de la

ACE, 14 (42) CC BY-ND 3.0 ES | UPC Barcelona, España | La génesis de los paseos litorales: el caso de la fachada marítima urbana de Alicante. DOI: http://dx.doi.org/10.5821/ace.14.42.8271 
guerra. Se podría afirmar que la fachada marítima de Alicante fue el escenario de los últimos sucesos de la contienda. A continuación, vendría la Posguerra, años difíciles de escasez económica y de reconstrucción de la ciudad. Fue en los años 40 cuando se reordenó la plaza del Mar, retirando el monumento a los mártires de la libertad dañado en la guerra (Figura 7, dcha.), que años después sería sustituido por una fuente que permanece en la actualidad.

En 1955 se inició una reforma integral del paseo, introduciendo el pavimento de mosaico de mármol tricolor con ondulaciones tan característico y que se ha convertido en seña de identidad de la ciudad (Figura 7, izda. inf.). En los años siguientes se ganó más terreno al mar, mejorándose la carretera litoral y ampliando el muelle de costa, a la vez que buena parte de las residencias decimonónicas eran sustituidas por edificios en altura. El esquema de circulaciones que presenta todo el conjunto en la actualidad es resultado de la puesta en funcionamiento del Plan Especial del Puerto de 1992, que eliminó la actividad comercial destinando la dársena al atraque de embarcaciones deportivas y de recreo. A su vez, se les dio continuidad a los dos tramos del paseo del muelle costero con la incorporación de palmeras y nuevo mobiliario urbano.

\subsection{El parque de Canalejas}

Situado al sur de la zona del Ensanche, delante de la actual avenida del Doctor Ramón y Cajal, se localiza junto a la costa, como prolongación hacia el sur de la Explanada. Es uno de los parques de mayor tamaño y más antiguos que se conservan en el centro urbano. Originado tras el derribo de las murallas y del baluarte de San Carlos, en un principio no fue más que una explanada que servía de varadero - así fue llamado durante décadas - y como lugar de acopio de mercancías del puerto. Aunque el proyecto de parque y jardinería es anterior, no sería hasta 1891 cuando por fin se convierte en un parque-paseo, consistente en un salón central con hileras longitudinales de pinos y palmeras en paralelo a la costa y circulación de carruajes en los laterales (Figura 8, dcha. sup.). Cuando estuvo concluido, en 1908, se le dio el nombre de Paseo de Canalejas, en honor al político liberal español, al igual que el monumento anejo que sirve de rótula en su encuentro con el paseo de la Explanada.

Figura 8. Parque de Canalejas

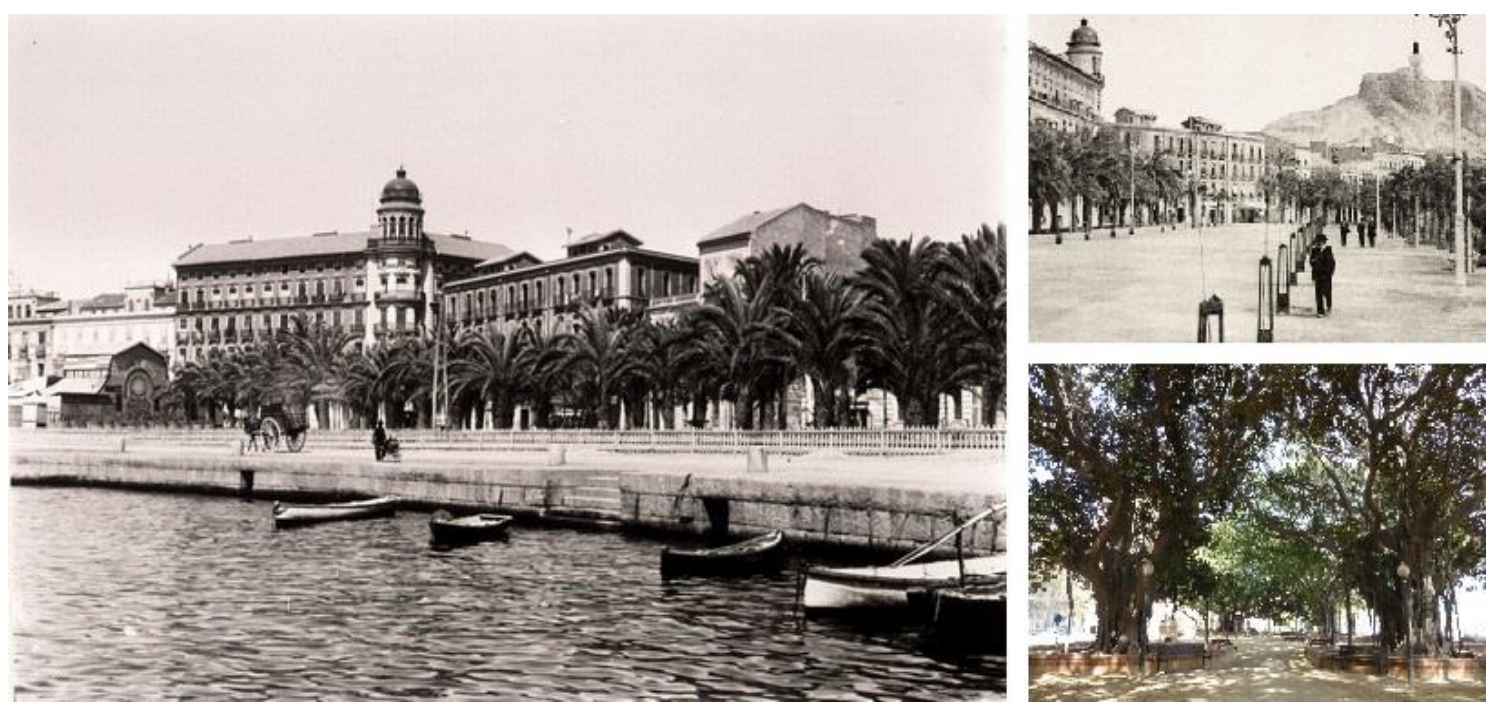

Notas: inicio del parque con el teatro de verano y Casa Alberola, año 1900 aprox. (izda.); año 1900 aprox. (dcha. sup.); año 2019 (dcha. inf.). Fuente: Archivo Municipal de Alicante (izda. y dcha. sup.) y autora (dcha. inf.). 
El límite físico que suponía el baluarte de San Carlos, que no se derribó completamente hasta bien entrada la segunda mitad del siglo XIX, y el hecho de que el último tramo de la calle San Fernando, que servía de trasera a las manzanas del parque, se abriera con posterioridad al resto hicieron que su desarrollo fuera algo diferente al que experimentó el Malecón. Sus construcciones no provenían de viviendas-almacén de comerciantes, sino que las parcelas resultantes se vendieron a gente adinerada que estableció allí su residencia o bien realizó una promoción de viviendas para alquiler a particulares, como es el caso de la Casa Alberola que todavía perdura parcialmente (Figura 8, izda.). El haber servido como lugar de acopio de mercancías durante años propició que diversas compañías de importación-exportación se establecieran en esta zona, por lo que en las primeras décadas convivieron residencias con almacenes.

En la actualidad, y prácticamente desde que se urbanizó, el parque se compone de una plataforma con suelo de tierra elevada en la que se estructura un paseo central longitudinal y dos calles laterales separadas por parterres, con abundante vegetación de árboles y arbustos. Se podría considerar dividido en dos tramos: una primera parte, hasta la intersección con la avenida Doctor Gadea, mucho más estructurada, con presencia de esculturas sobre pedestales, secuencia de bancos y farolas, fuente, alcorques de forma poligonal, etc., al estilo decimonónico; una segunda parte, hasta la plaza Galicia, mucho más inconexa.

Albergó durante varios años, a principios del siglo XX, el teatro de verano, una edificación de carácter estacional que se levantaba en la época estival como parte de las actividades de recreo que amenizaban el tiempo libre de los visitantes que llegaban a Alicante a tomar los baños de mar (Figura 8, izda.). A pesar de la sencillez de la construcción, toda ella en madera, contaba con una fachada de estilo modernista, en consonancia con algunos balnearios, al gusto de la época.

Cuenta con varios ejemplares de ficus catalogados (Figura 8, dcha. inf.), que llegan a medir treinta metros de diámetro de copa, así como dos robles australianos (Ramos, 2015), lo que le confiere amplias zonas de sombra y espacio para juego de niños y reposo. Esta morfología de parque, más que de paseo, y el hecho de estar más alejado del casco histórico y de la playa, hace que sea menos transitado que la Explanada, aunque ello no le resta protagonismo en una ciudad donde escasean los espacios verdes.

\subsection{El paseo de Gómiz}

Con unos 830 metros de longitud, es el paseo litoral continuador de la Explanada hacia el norte, que sirve de marco a la playa urbana de Alicante, la playa del Postiguet. Situado junto al centro tradicional, recorre el frente costero, desde el puerto hasta el final de la playa, junto a la estación de La Marina. Surgido bajo la idea inicial de crear una fachada marítima continua, fue el último de los paseos litorales en tomar forma, tras el éxito de la Explanada y del parque de Canalejas.

La playa del Postiguet, junto al monte Benacantil, siempre ha estado ligada a la historia de la ciudad. No solo fue puerto natural donde embarcaban las tropas, sino también testigo del desembarco de filas enemigas y lugar elegido por los pescadores para el varado de sus barcas. Frente a ella y al abrigo de la montaña, desde la primera medina árabe, creció un núcleo de viviendas extramuros, morada primero de judíos y posteriormente de marineros y pescadores, que daría lugar al barrio del Raval Roig que conocemos hoy. Desde mediados del siglo XIX, esta playa fue espacio de concentración de los balnearios a los que llegaban visitantes del interior para tomar los baños.

Del año 1890, en pleno auge de la balneoterapia, es la autorización para la creación del paseo (Ramos, 1984). Con planos de J. Porrúa, se trataba de un paseo bulevar prolongación de la Explanada, continuando con sus hileras de palmeras, y una calzada exterior de circulación de vehículos para 
facilitar el acceso a las casas de baños. La particularidad de este paseo, que lo condicionaría en gran medida, era que se hallaba limitado en su encuentro con la ciudad por un entramado de vías de ferrocarril que comunicaban con el puerto y con la cercana estación.

La pretensión de crear una fachada marítima continua, como prolongación de los otros paseos existentes, se fue un poco al traste en este tercer y último tramo del borde litoral. Las razones fueron, por un lado, la orografía del terreno (la proximidad del monte Benacantil), que motivó que las construcciones que hacían de frente costero - el barrio Raval Roig- se encontraran unos metros elevadas por encima del nivel del mar, con la desconexión a nivel de cotas que eso provocaba, sumado a la barrera de las vías de tren (Figura 9, centro) y, posteriormente, de circulación de vehículos. Además, el Raval era un barrio humilde, muy alejado de las monumentales residencias de la Explanada. Por otro lado, la instalación en la playa de los balnearios provocó que durante décadas este espacio estuviera destinado a dar servicio a los bañistas. Todo ello dio a este paseo unas características propias muy particulares.

Tras el paréntesis de la Guerra Civil y la completa desaparición de los balnearios a finales de los años 60 , esta zona de la ciudad entraría en la siguiente década completamente remodelada y mucho más accesible (Figura 9, izda.). Las sombrillas y chiringuitos sustituyeron a los balnearios. Se desmanteló la barrera de las vías del tren, aunque el tráfico del vial longitudinal - nacional 332 - fue en aumento a la vez que lo hacía el parque automovilístico, y así permanece en la actualidad, lo que imposibilita la percepción de la playa como un elemento continuador de la trama urbana. De esos años es el pavimento en mosaico característico, al igual que el Apartotel Meliá, edificio de promoción privada de grandes dimensiones levantado en una plataforma ganada al mar en terrenos públicos junto al muelle de Levante que, no exento de polémica, hace de biombo separador entre la playa y el puerto (Varela, 1980).

Con el auge del turismo y las vistas al mar como reclamo, la mayor parte de las viviendas del Raval Roig fueron sustituidas por edificios en altura, rompiendo con la estructura tradicional del barrio litoral.

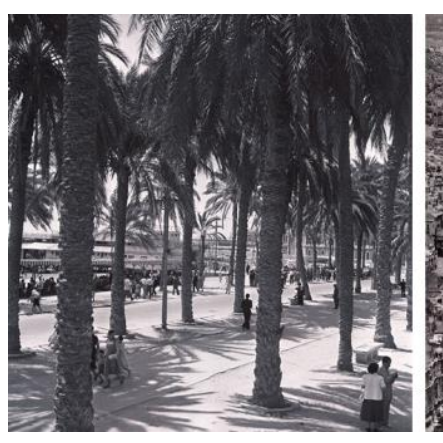

Figura 9. Paseo de Gómiz
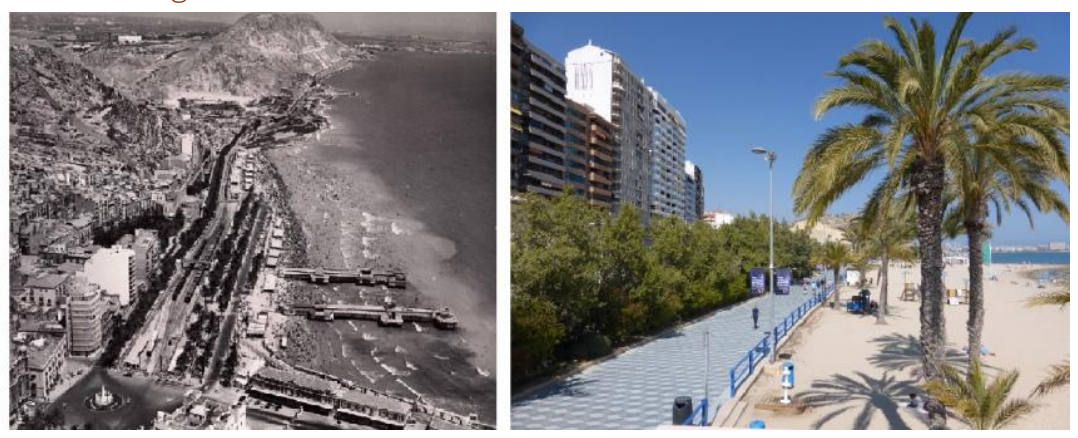

Notas: año 1950 (izda.); vista aérea del paseo de Gómiz y de la playa del Postiguet con los balnearios, año 1966 (centro); año 2019 (dcha.). Fuente: Archivo Municipal de Alicante (izda. y centro) y autora (dcha.).

En la actualidad, el Paseo de Gómiz y su entorno es uno de los espacios públicos más concurridos de la ciudad, frecuentado por visitantes y locales por ser uno de los mejores lugares de Alicante para el deporte, el ocio y el contacto directo con la naturaleza, y todo ello a escasos metros de distancia del centro urbano. 


\section{Conclusiones}

El análisis e interpretación de todas las fuentes consultadas componen una imagen secuencial, nítida y estructurada de cuál ha sido la morfología de la fachada marítima urbana de Alicante desde sus orígenes hasta nuestros días. La investigación trata de dar respuesta a la cuestión planteada al inicio sobre si la aparición de los paseos litorales urbanos se deriva de un cambio de función en la fachada marítima y en qué momento y por qué se produce esa transformación.

El estudio de la evolución y desarrollo del frente litoral alicantino en su contexto histórico permite afirmar que éste fue variando a lo largo de los siglos, adaptándose a las necesidades económicas, políticas y sociales del momento. La morfología del interfaz tierra-mar fue mutando, como cara visible de una ciudad en continua transformación, incapaz de permanecer ajena al devenir de los tiempos.

Si bien la función de defensa por mar de la ciudad, en forma de murallas costeras, fue la predominante a lo largo de los siglos, ésta se compaginó con la de servir de entorno urbano y comercial del puerto. Estos dos roles primigenios de la fachada marítima, defensiva y de marco portuario, se dieron de forma coetánea e inseparable. Por un lado, Alicante siempre ha sido enclave portuario, y su crecimiento y evolución se debió a la creciente actividad comercial que en torno a él se desarrollaba. Por otro lado, había que defender la ciudad porque el establecimiento de mercaderes dependía en gran medida de la consecución de un puerto y una urbe seguras, ya que sin ellos no había actividad comercial. En definitiva, el inseparable binomio puerto-ciudad.

El punto de inflexión se produjo a mediados del siglo XIX, cuando Alicante dejó de ser plaza fuerte y se autorizó el derribo de las murallas. La función defensiva del frente, a partir de entonces, dejó de tener sentido. Ya durante el siglo XVIII había aparecido un nuevo espacio público en la ciudad, el Malecón, terreno ganado al mar con el vertido de los escombros de derribo y que en un principio fue un lugar residual ligado al puerto. Con el paso del tiempo, y el comienzo de la ordenación urbana, se urbanizó como paseo, la Explanada, y las iniciales casas-almacén de comerciantes próximas al muelle dieron paso a edificios residenciales de la burguesía, que eligió vivir frente al mar junto a uno de los espacios más emblemáticos del Alicante de finales del siglo XIX. Tras ese proceso, la función representativa había sustituido completamente a la defensiva.

A la creación del nuevo paseo le siguió, unas décadas después, la urbanización de dos paseos más como prolongación del original: el Parque de Canalejas, hacia el sureste, y el Paseo de Gómiz, hacia el noreste, junto a la playa del Postiguet. Estos tres espacios públicos consecutivos, aunque con estructura, evolución y morfología diferentes, recorren la línea de costa paralelamente al mar, vertebrando la fachada marítima urbana de Alicante en la actualidad.

Trazados originariamente siguiendo las ideas higienistas decimonónicas, los paseos sirvieron de marco, no solo a las residencias de las clases pudientes locales, sino también como espacio de recreo de los visitantes del interior que llegaban a Alicante para tomar los baños de mar, que tan de moda se habían puesto en la segunda mitad del siglo XIX y que el ferrocarril favoreció. Esa función lúdicorepresentativa del frente marítimo se prolongaría mientras siguió en boga el turismo de balnearios que, con la popularización del automóvil en los años 60 y 70, fue dando paso paulatinamente al turismo de sol y playa. Tras unas décadas de un cierto letargo y abandono, el frente costero recuperó parte de su antiguo protagonismo, sobre todo con la reconversión de la dársena en marina de recreo y el traslado de las instalaciones portuarias al sur de la ciudad en los años 90 del pasado siglo. En esta época se reordenaron los paseos, se dio uso distinto a los muelles y se levantaron nuevas edificaciones destinadas a los deportes náuticos y el ocio. 
Se podría afirmar que la función principal que la fachada marítima urbana realiza actualmente es la lúdico-representativa, dado que actúa de foco de atracción de los turistas que eligen Alicante como destino de vacaciones y ejerce de elemento representativo de la ciudad. El rol de marco portuario queda como un apunte meramente anecdótico, dado que las embarcaciones de recreo que engalanan hoy el frente litoral no son más que el recuerdo vivo de lo que un día la ciudad fue: un puerto de mar.

Conflicto de intereses: La autora declara que no hay conflicto de intereses.

\section{Bibliografía}

Aguilar, I. (Dir.). (2008). 150 años de ferrocarril Alicante-Madrid (1858-2008). Valencia, España: Conselleria d'Infraestructures i Transport.

Aldana, S. (Dir.) et al. (2004). Monumentos desaparecidos de la Comunidad Valenciana. Alicante. Valencia, España: Generalitat Valenciana, Consell Valencià de Cultura.

Aller y Vicente, J. (1900). Guía de Alicante para el año 1900. Alicante, España: Such, Serra y Cia.

Alonso, M. et al. (1990). Alicante: V siglos de Arquitectura. Alicante, España: Colegio Oficial de Arquitectos de la Comunidad Valenciana, Demarcación de Alicante.

Bendicho, V. (1960). Crónica de la Muy Ilustre, Noble y Leal Ciudad de Alicante, acabada en la ciudad el año del Señor 1640. Alicante, España: Instituto de Estudios Alicantinos.

Bevià, M. y Varela S. (1994). Alicante: Ciudad y Arquitectura. Alicante, España: Fundación Cultural CAM.

Blasco, C. et al. (1996). El frente marítimo de Alicante. En II Jornadas de Geografía Urbana. Las fachadas urbanas marítimas y fluviales (pp. 365-378). Alicante, España. Recuperado de http://rua.ua.es/dspace/handle/10045/20479

Bruttomesso, R. (2004). Complejidad en la relación puerto-ciudad. Revista I.T, (67), 22-31. Recuperado de: http://static.omau-malaga.com/omau/subidas/archivos/7/6/arc 7767.pdf

Calduch, J. y Varela, S. (1979). Guía de Arquitectura de Alacant. Tomo 1‥ Alicante, España: Comisión de Publicaciones C.S.I. del Colegio de Arquitectos de Alicante.

Campos, S. (2007). Historia Gráfica del Puerto de Alicante. Madrid, España: Autoridad Portuaria de Alicante.

Domingo, J. (2014). El plano geométrico general de Alicante de 1849: estudio y reconstrucción digital. EGA. Revista de Expresión Gráfica Arquitectónica (23), 226-235. DOI: http://dx.doi.org/10.4995/ega.2014.2177

Gastaldi, F. y Camerin, F. (2017). El proceso de remodelación del waterfront de Génova y los proyectos de Renzo Piano desde los años 80 hasta el Blue Print. ACE: Architecture, City and Environment (11)33, 33-64. DOI: $\underline{\text { http://dx.doi.org/10.5821/ace.11.33.4683 }}$ 
Gastaldi, F. y Camerin, F. (2018). Transformaciones urbanas y grandes eventos en Italia y España a partir de 1992. Ciudad y Territorio. Estudios Territoriales (L)196, 201-216. Recuperado de https://www.fomento.es/CVP/handlers/pdfhandler.ashx?idpub=BP1025

Giménez, E. et al. (1985). Sobre la ciudad dibujada de Alicante, del plano geométrico al plan general de 1970. Alicante, España: Colegio Oficial de Arquitectos de Valencia.

González, A. B. (2012). Los inicios de la fortificación abaluartada en Alicante, la muralla de Carlos V. En IV Congreso de Castellología (p. 787-800). Madrid, España.

Grao-Gil, O. (2020). Construcciones efímeras en madera: los balnearios de la fachada marítima de Alicante (siglos XIX y XX). Informes de la Construcción (560). DOI: https://doi.org/10.3989/ic.72887

Guardiola, J. (1895). Reformas en Alicante para el siglo XX. Alicante, España: Imp. de J. J. Carratala.

Jaén, G. (Dir.) et al. (1999). Guía de Arquitectura de la Provincia de Alicante. Alicante, España: Instituto de Cultura Juan Gil-Albert y Colegio Territorial de Arquitectos de Alicante.

Jaén, G. y Gutiérrez, P. J. (2014). Jardines románticos en Alicante. Canelobre, (64), 468-481.

Madoz, P. (1846) Diccionario geográfico-estadístico-histórico de España y sus posesiones de ultramar. Madrid, España: Imprenta del Diccionario Geográfico estadístico-histórico de Pascual Madoz.

Martí, P. et al. (2018). Frentes marítimo-fluviales en ciudades españolas: nuevos espacios urbanos. Bitácora Urbano Territorial, 28(3), 71-79. DOI: http://dx.doi.org/10.15446/bitacora.v28n3.72186

Martínez, A. (1998). Arquitectura de la ciudad de Alicante 1923-1943: la aventura de la Modernidad. Alicante, España: Instituto Alicantino de Cultura Juan Gil-Albert y Colegio de Arquitectos de Alicante.

Martínez, C. (2015). Un proyecto central en la formación moderna de Cartagena: la estación ferroviaria como rótula entre barrios (1896, 1900-1906, 2006). ACE: Architecture, City and Environment (11)29, 85103. DOI: $\underline{\text { http://dx.doi.org/10.5821/ace.10.29.3775 }}$

Martínez, P. (8 de marzo de 2018). La Volvo Ocean Race 2017/18 generó 96 millones de euros de PIB y 1700 empleos en España Expansión. Recuperado de https://www.expansion.com/nauta360/volvoocean-race/2018/03/08/5aa1033246163faa488b4628.html

Melgosa, F. J. (2000). Turismo de salud: Termalismo y balnearios, en la obra colectiva. En /// Congreso de turismo universidad y empresa (p. 359-386). Valencia, España: Tirant lo Blanch.

Olmo del, M. (coord.). (2016). Guerra Civil y memoria histórica en Alicante. Alicante, España: Archivo Histórico Provincial de Alicante y Dirección General de Cultura GVA.

Ponce, G. y Dávila, J. M. (1998). Medidas higienistas y planes de reforma urbana en el tránsito de los siglos XIX al XX en las principales ciudades de la provincia de Alicante. Investigaciones Geográficas (20), 141-159. DOI: http://dx.doi.org/10.14198/INGEO1998.20.07

Ramos, A. (1984). Evolución urbana de Alicante. Alicante, España: Instituto de estudios Juan Gil-Albert. Ramos, J. (2015). Jardines Históricos de la Provincia de Alicante. Alicante, España: Diputación de Alicante.

ACE, 14 (42) CC BY-ND 3.0 ES | UPC Barcelona, España | La génesis de los paseos litorales: el caso de la fachada marítima 
Reyero, C. (2014). La imagen del frente marítimo de Alicante como lugar representativo y espacio de representación. Del siglo XIX a la primera modernidad. Canelobre, (64): 426-437.

Rosser, P. (1990). Origen y Evolución de las Murallas de Alicante. Alicante, España: Patronato Municipal para la conmemoración del Quinto Centenario de la Ciudad de Alicante.

Sánchez, E. y Guardiola, J. (1894). Memoria Higiénica de Alicante. Alicante, España: Establecimiento Tipográfico de Costa y Mira.

Subirá, G. (1987). Evolución histórica del puerto de Alicante. Alicante, España: Caja de Ahorros Provincial de Alicante.

Varela, S. (1980). Guía de Arquitectura de Alacant. Tomo 2‥ Alicante, España: Comisión de Publicaciones C.S.I. del Colegio de Arquitectos de Alicante.

Vera, J. F. (1987). Turismo y urbanización en el litoral alicantino. Alicante, España: Instituto de Estudios Juan Gil-Albert.

Viciana de, M. (1971). Chrónica de la ínclita y coronada ciudad de Valencia y su reyno (1564). Alicante, España: Imp. Such, Serra y Co.

Viravens y Pastor, R. (1876). Crónica de la muy ilustre y siempre fiel ciudad de Alicante. Alicante, España: Imprenta de Carratalá y Gadea.

Zaragoza, J. (Dir.). (2007). Mercados de Alicante: mil años de historia. Alicante, España: Ayuntamiento de Alicante. 